\title{
REVIEW
}

\section{Clinical review: Lung imaging in acute respiratory distress syndrome patients - an update}

\author{
Davide Chiumello $^{1 *}$, Sara Froio ${ }^{1}$, Belaïd Bouhemad ${ }^{2}$, Luigi Camporota ${ }^{3}$ and Silvia Coppola ${ }^{1}$
}

\begin{abstract}
Over the past 30 years lung imaging has greatly contributed to the current understanding of the pathophysiology and the management of acute respiratory distress syndrome (ARDS). In the past few years, in addition to chest $X$-ray and lung computed tomography, newer functional lung imaging techniques, such as lung ultrasound, positron emission tomography, electrical impedance tomography and magnetic resonance, have been gaining a role as diagnostic tools to optimize lung assessment and ventilator management in ARDS patients. Here we provide an updated clinical review of lung imaging in ARDS over the past few years to offer an overview of the literature on the available imaging techniques from a clinical perspective.
\end{abstract}

\section{Introduction}

Acute respiratory distress syndrome (ARDS) is characterized by diffuse alveolar damage, associated with an increase in alveolar and capillary permeability leading to accumulation of interstitial and alveolar edema that requires mechanical ventilation [1].

Over the past 30 years, the repertoire of lung imaging has evolved from just chest X-ray to include functional imaging techniques that have increased the understanding of the relationship between lung structure and function in ARDS. Furthermore, the recent 'Berlin' definition of ARDS attempted to clarify the role of lung imaging in the definition of the syndrome in order to increase agreement between intensivists and radiologists and to facilitate the application of the definition in clinical practice [2-4]. The aim of this review is to provide an updated overview of the literature from the past few years,

\footnotetext{
*Correspondence: chiumello@libero.it

'Dipartimento di Anestesia, Rianimazione (Intensiva e Subintensiva) e Terapia del Dolore, Fondazione IRCCS Ca' Granda - Ospedale Maggiore Policlinico, Via F. Sforza 35, Milan, Italy

Full list of author information is available at the end of the article
}

focusing on the role of chest X-ray, computed tomography $(\mathrm{CT})$, lung ultrasound (LUS), positron emission tomography (PET), electrical impedance tomography (EIT) and magnetic resonance imaging (MRI) in lung assessment, ventilator management and outcome in ARDS patients. We underline the role of each lung imaging technique in the evaluation of recruitment, overdistension and lung perfusion that result in, or are influenced by, mechanical ventilation. In addition, we summarize the main findings on the outcome and possible risks of intra-hospital transport to the radiology department and $\mathrm{X}$-ray irradiation. Our review completes and extends two recent reviews on lung imaging in ARDS [5,6].

\section{Review}

Lung assessment and technical aspects

Chest X-ray

For almost 20 years, the evaluation of the extension and distribution of lung opacities in ARDS patients had been limited to only chest X-rays. In the first 24 hours following insult, when there is little alveolar edema, chest Xrays can appear quite normal [7]. When ARDS evolves, a widespread opacification becomes apparent and during the following 2 to 3 days the chest X-ray can show bilateral, more or less homogeneous air space opacifications due to exudation of inflammatory fluid into the interstitium and air spaces independent of its etiology [8]. This finding was also confirmed during the recent H1N1 pandemic infection, where a patchy multifocal consolidation was the most frequent abnormality presenting in patients who developed ARDS [9]. Lichtenstein and colleagues [10] reported lower accuracy with bedside chest $\mathrm{X}$-ray in detecting pleural effusion (47\%), alveolar consolidation (75\%) and alveolar interstitial syndrome $(72 \%)$ compared to LUS. Similarly, Xirouchaki and colleagues [11] demonstrated that bedside chest X-ray had lower diagnostic accuracy for pleural effusions (69\%), pneumothorax (89\%) and alveolar consolidation (49\%) compared to LUS and CT. Also, Endo and colleagues [12] found that ARDS subsequently developed within 3 days in up 
of $50 \%$ of patients admitted with acute respiratory failure but without any lung abnormalities on chest X-ray, suggesting that chest $\mathrm{X}$-ray might be insufficient to detect lung alteration in the initial stages of the disease. In the new ARDS definition the radiographic criterion is more explicit, specifying that it should include bilateral opacities, consistent with pulmonary edema not fully explained by effusions, lobar/lung collapse or nodules. In fact, when the radiological criteria of the previous ARDS definition were strictly applied (bilateral chest X-ray infiltrates), the sensitivity was good but specificity was low [3].

A possible additional use of chest X-ray in guiding fluid management, when intravascular pressure measurements are unavailable, could be the measurement of the vascular pedicle width, which correlates with the pulmonary artery occlusion pressure and changes in intravascular volume status [13].

\section{Computed tomography}

CT has been used to study the inhomogeneous pattern of lung lesions in ARDS since the 1980s [14]. The classical morphological CT description includes the recognition of normally aerated lung, poorly inflated areas, characterized by increased density but with still recognizable vessels (ground-glass opacifications) and uninflated areas with increased density and no recognizable vessels (consolidation) [15]. In the acute phase of ARDS there is a combination of alveolar flooding (edema), interstitial inflammation and compression atelectasis [16] with an increase in lung tissue and a reduction in lung gas volume [17]. The degree of lung aeration depends on the transpulmonary pressure and surfactant [18-20]. The transpulmonary pressure is affected by the anterioposterior and cephalocaudal gradients, which are influenced by lung weight, abdominal pressure and the weight of the mediastinum [18,21]. ARDS patients can present with different lung morphologies: diffuse bilateral attenuations ('white lung') or focal CT attenuations ('white lung' in the lower lobes with 'black lung' in the upper lobes). Lung CT mainly reflects the intensity of lung aeration loss; in fact, patients with diffuse or lobar attenuations present comparable amounts of excess lung tissue (that is, edema and inflammation) despite differences in radiological presentation. The only difference between the two groups was the degree of aeration in the upper lobes, which was significantly reduced in patients with lobar attenuations (Figure 1) [17]. Lung morphology clearly determines the response to positive end-expiratory airway pressure (PEEP) [22], recruitment maneuvers [6,23-25] and prone position $[15,26]$. Subsequently, the architecture of the lung can show extensive modifications due to diffuse parenchymal fibrosis and pulmonary bullae, which have

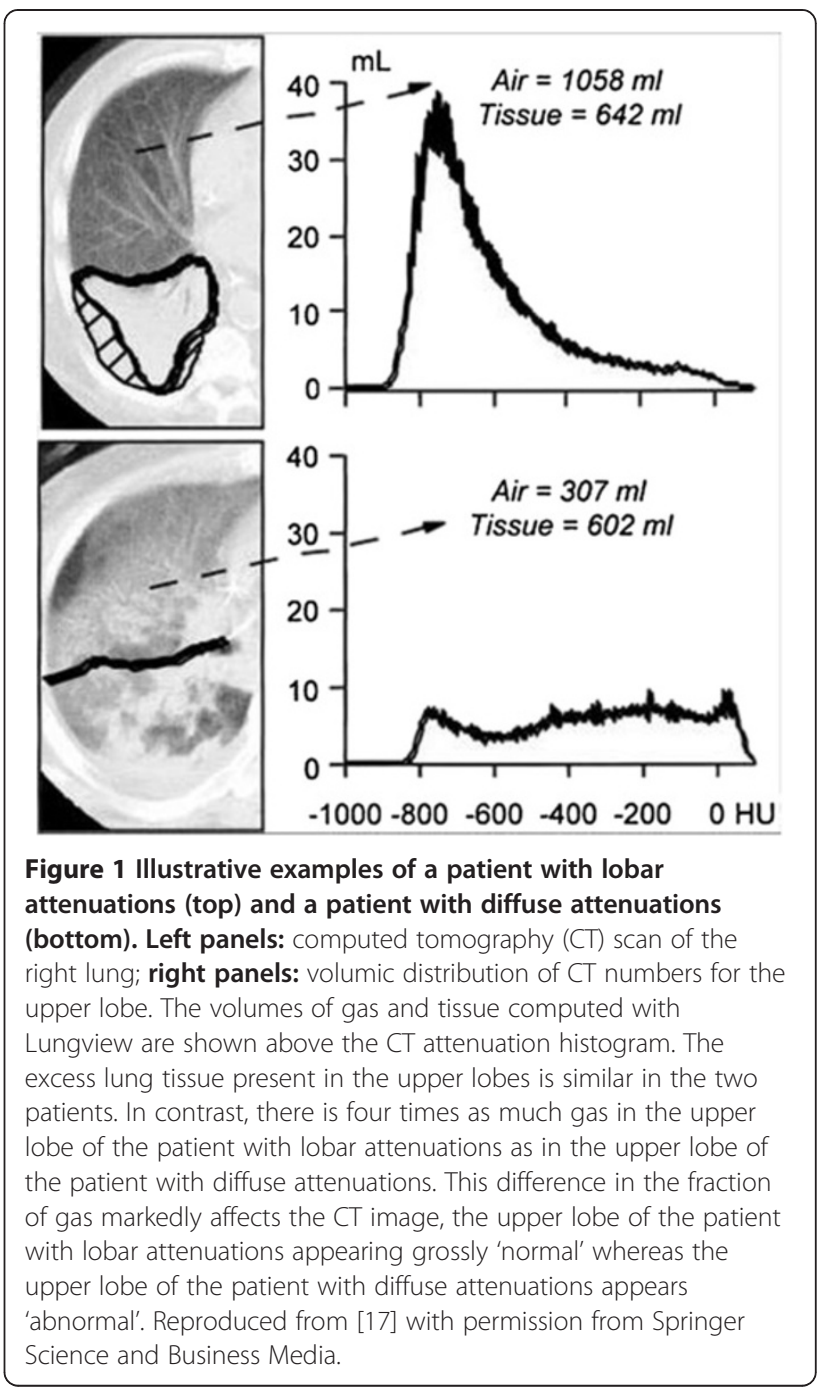

been correlated with prolonged ventilation [27]. In addition to higher sensitivity compared to chest X-ray [15], CT scan can measure the volume/weight of lung abnormalities (masses, nodules, contusions and edema). Wang and colleagues [28] reported that the volume of pulmonary contusions in blunt chest trauma was an independent predictor factor for ARDS. Similarly, Strumwasser and colleagues [29] found that a pulmonary contusion volume greater than $20 \%$ of the total lung volume predicted, with good sensitivity and specificity, the development of ARDS. However, quantitative analysis of the whole lung is labor intensive and time consuming, as it requires the manual delineation of each lung section. To shorten the time required for lung CT analysis and favor more frequent application in critically ill patients, Reske and colleagues [30] showed that analysis of 10 thoracic CT sections provided similar results to analysis of the whole lung. This could be a further step for a more widespread clinical use of CT [31]. 
Although CT presents several advantages, its use was not demanded as a criterion for the definition of ARDS because of considerations about cost, safety, lack of widespread availability and feasibility. Conversely, in the new ARDS definition, bilateral opacities seen on CT scan, where available, could substitute for the criteria of chest X-ray opacities [3]. However, the benefits of CT scan imaging in the clinical setting have to be weighed against the risks associated with transporting a patient from the ICU to the radiology department, the economic costs and the burden of radiation exposure.

\section{Lung ultrasound}

Transthoracic LUS is a noninvasive, easily repeatable and reproducible bedside technique [32]. It allows the diagnosis of alveolar-interstitial syndrome, lung consolidation, pleural effusion, and pneumothorax more accurately than auscultation and chest X-ray in critically ill patients [10,33-35]. Recently, evidence-based and expert consensus recommendations for LUS with a focus on emergency and ICU settings were provided [36].

The creation of an ultrasound image is based on the physical properties of ultrasound pulse formation, the propagation of sound in matter and the interaction of sound waves with reflective interfaces [34]. Normally, lung parenchyma is not visible beyond the pleura. Thus, the ability to obtain real images of lung parenchyma always indicates pathology [37]. Basic LUS signs can be grouped into A lines, B lines (comet tails) and consolidation [36]. To summarize, four patterns corresponding to various degrees of lung aeration can be described [36]: first, the presence of artifactual horizontal A lines beyond the pleural line characterizes normal pulmonary aeration; second, the presence of multiple and well separated vertical $\mathrm{B}$ lines corresponds to a moderate decrease in lung aeration resulting from interstitial syndrome; third, the presence of coalescent $B$ lines less than $3 \mathrm{~mm}$ apart corresponds to a more severe decrease in lung aeration resulting from partial filling of alveolar spaces by pulmonary edema or confluent bronchopneumonia [38]; and fourth, the presence of lung consolidation containing white points characterized by an inspiratory reinforcement - dynamic bronchograms - corresponds to complete loss of lung aeration with persisting aeration of distal bronchioles.

The heterogeneous distribution of LUS patterns, including well separated or coalescent B lines, spared areas and presence of posterior lung consolidations with dynamic bronchograms, is typical of ARDS and allows its early distinction from acute cardiogenic pulmonary edema [39].

LUS is performed at the bedside, avoiding the possible risks associated with transporting the patient outside the ICU. Cianchi and colleagues [40] reported the experience of daily LUS in a group of patients with severe ARDS due to $\mathrm{H} 1 \mathrm{~N} 1$ infection. Alveolar interstitial syndrome (moderate or severe) and consolidation were present in all ultrasound examinations. LUS significantly reduced the number of chest X-rays and $\mathrm{CT}$ scans performed. However, LUS is of limited usefulness in obese patients and in the presence of subcutaneous emphysema or large thoracic dressings and it requires an adequate period of training.

\section{Positron emission tomography}

PET is a functional imaging technique based on the administration of a molecule labeled with a radioactive isotope that decays with the emission of a positron. PET with [18F]-fluoro-2-deoxy-D-glucose (18-FDG) has been used to monitor cellular metabolic activity believed to reflect the presence and activity of inflammatory cells in the setting of lung inflammation [41,42]. There are different methods for quantifying FDG uptake in the lung: the simplest are based on static indices, such as the standardized uptake value, defined as the tissue concentration of tracer as measured by the PET scanner divided by the activity injected divided by the body weight [41]. Dynamic indices are also derived from the kinetics of FDG, typically over a period of 60 to 75 minutes starting from the endovenous injection of the radio-tracer [43]. These dynamic indices, based on lung-specific compartmental models, account for the presence of the extracellular compartment and are influenced by the number of metabolically active cells and the diffusion of radiotracer into edematous tissue. Bellani and colleagues [44] showed that, in a cohort of 10 mechanically ventilated patients with ARDS, inflammation was not confined to the regions with density abnormalities on the CT scan (non-aerated or poorly aerated regions), but also involved normally aerated regions, confirming previous data from quantitative lung CT scans in ARDS patients [17]. Previously, Rodrigues and colleagues [45] observed only moderate 18-FDG uptake in non-aerated and poorly aerated regions in blunt chest trauma patients who did not develop ARDS, while in subjects who subsequently developed ARDS, diffuse 18-FDG uptake was identified 1 to 3 days before clinical manifestation of disease. PET has made important contributions to understanding of the relationship between lung imaging and lung injury (Figure 2).

Among the principle mechanisms suggested to lead to ventilator-induced lung injury, excessive pressure (barotrauma) or volume (volotrauma) and cyclic recruitment and derecruitment with different intensities have been proposed [46-50]. Using PET, Bellani and colleagues [51] found that the amount of tissue undergoing cyclic recruitment and derecruitment was quite low, around 3\% of the total lung weight. No difference was found in 

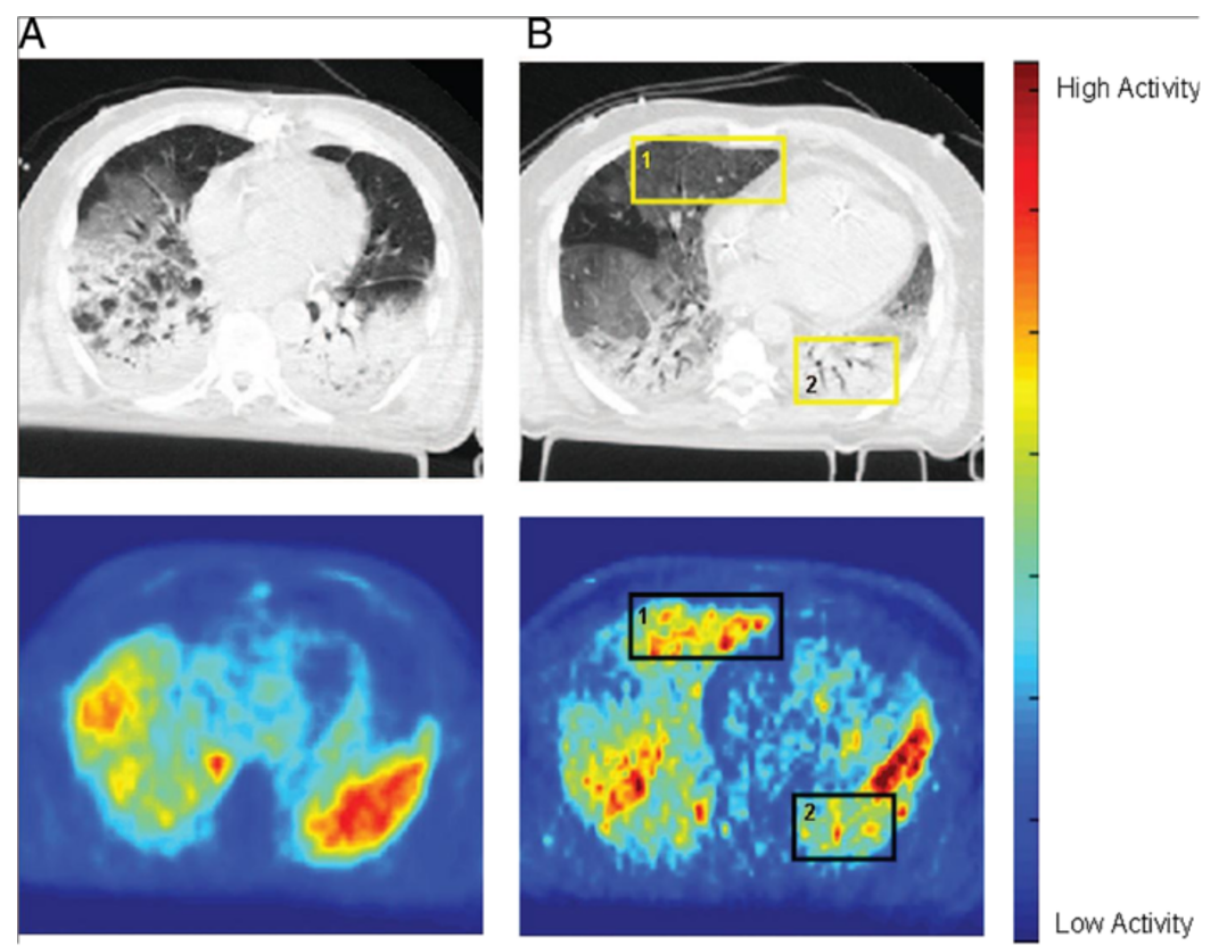

Figure 2 Representative images of cross-registered computed tomography (CT) and [18F]-fluoro-2-deoxy-D-glucose (18-FDG) positron emission tomography from two patients with acute lung injury/acute respiratory distress syndrome. The $C T$ image was acquired during a respiratory pause at mean airway pressure. The gray scale is centered at -500 Hounsfield units with a width of 1,250 Hounsfield units. Positron emission tomographic images represent the average pulmonary 18-FDG concentration during the last 20 minutes of acquisition (from 37 to 57 minutes since 18-FDG administration); the color scale represents radioactivity concentration ( $\mathrm{kBq} / \mathrm{ml}$ ). (A) 18-FDG distribution parallels that of the opacities detected on CT. (B) Intense 18-FDG uptake can be observed in normally aerated regions (square 1), while activity is lower in the dorsal, 'non-aerated' regions of both lungs (square 2). Reproduced from [44] with permission from Wolters Kluwer Health.

metabolic activity between these regions and the collapsed regions. However, the metabolic activity of the normally aerated tissue significantly increased at an airway plateau pressure higher than $26 \mathrm{cmH}_{2} \mathrm{O}$.

PET has also been used to measure the effect of antiinflammatory interventions, suggesting its applicability for testing novel drugs [52]. Similarly to CT, PET requires the transportation of patients outside the ICU with a long stay in the PET facility.

\section{Electrical impedance tomography}

EIT is a non-invasive, bedside monitoring technique that provides semi-continuous, real-time information about the regional distribution of changes in the electrical resistivity of lung tissue due to variations in ventilation (or blood flow/perfusion) in relation to a reference state $[53,54]$. EIT data can only indirectly quantify the relative changes in local lung impedance. From this, it is obvious that only functionally active lung structures are displayed, whereas structures - either normal or pathological (for example, stable pneumothoraces or pleural effusions) - that do no change over time are functionally mute and cannot be represented as an image [55].
Several studies have validated EIT against other methods that measure global (for example, nitrogen washout-washin) or regional lung volume (for example, PET, CT, and single-photon emission CT) $[56,57]$. However, this linear correlation is crucially dependent on electrode position, conformational changes of the chest wall and diaphragm and the proportion of tidal ventilation distributed in the lung areas falling inside and outside the EIT image during tidal breathing [58].

\section{Magnetic resonance imaging}

MRI is a functional technique that offers the possibility to investigate the pathophysiology of pulmonary disease. Although conventional lung MRI offers poor signal intensity due to low proton density and the short $\mathrm{T} 2$ * relaxation time of lung tissue, hyperpolarized noble gas MRI can provide information about ventilationperfusion heterogeneity, pulmonary end-capillary diffusion of oxygen and lung microstructure with high spatial resolution $[59,60]$.

Noble gases such as Helium-3 and Xenon-129 can act as contrast agents, diffusing rapidly into airspaces to enable visualization and quantification of ventilated 
airways and alveolar spaces [61]. Hyperpolarized Xenon129 follows the same pathway as oxygen, diffusing from alveolar gas spaces to septal tissue and blood, and therefore allows the calculation of gas exchange parameters, including alveolar surface area, septal thickness and vascular transit time [61-63]. Visualization of ventilation is also possible using oxygen-enhanced MRI [61]. Recent studies have shown that MRI can enable calculation of alveolar size based on the MRI apparent diffusion coefficient $[60,63]$. This can be used to assess the effects of atelectasis and alveolar recruitment maneuvers [59].

\section{Recruitment}

\section{Chest X-ray}

Wallet and colleagues [64], in a group of ARDS patients, showed a good correlation between changes in lung density computed from digitally processed chest X-ray by a visual scale (that is, an estimation of lung recruitment) and lung recruitment measured from the pressure volume curve at two different levels of PEEP. However, this method requires manual delineation of seven polygonal regions of interest in the posterior intercostal spaces, using dedicated software in anesthetized and paralyzed patients and only the ratio of densities between each PEEP can be calculated [64]. At the present time, therefore, this method can not be routinely used [65].

\section{Computed tomography}

Lung recruitment can be computed as the decrease in non-inflated lung tissue, which represents the amount of non-inflated tissue that regains inflation [66], or as the increase in gas volume in the poorly and non-aerated tissue [67]. Comparison of these two methods, although not considering the same lung size, showed that they were not related. The first method underestimated lung recruitment compared to the second one, probably because, as stated by the authors, it did not take into account lung recruitment in the poorly aerated lung regions $[66,67]$.

Lung morphology (focal, diffuse or patchy loss of aeration) can significantly affect the response to lung recruitment. Following PEEP or a recruitment maneuver, patients with a diffuse loss of aeration showed significantly higher lung recruitment and long-lasting improvement in oxygenation compared to patients with a focal loss of aeration [6,22-25].

Several previous studies using CT to compute lung recruitment found that the amount of recruitable lung tissue, following recruitment maneuvers or the application of PEEP, was highly variable and it was difficult to predict at the bedside based on respiratory physiological variables $[5,68]$. Consequently, application of similar PEEP levels could induce significant differences in lung recruitment and lung strain [69]. Caironi and colleagues
[46] found that the application of high PEEP levels in patients with high lung recruitability significantly reduced the amount of opening and closing lung tissue without changing alveolar strain compared to patients with low lung recruitability. The opening and closing lung tissue was distributed mainly in the dependent lung regions and was an independent mortality risk factor. In addition to the PEEP, the size of tidal volume could also modulate the amount of opening and closing lung tissue. Bruhn and colleagues [70] compared the effect of high versus low tidal volume on the opening and closing lung regions. Increasing tidal volume from 6 to $12 \mathrm{ml} / \mathrm{kg}$ of body weight induced a significant reduction in nonaerated lung tissue with a higher amount of opening and closing lung regions. In addition to the application of PEEP, the lung could be recruited by the administration of exogenous surfactant. Lu and colleagues [71] showed that surfactant induced a significant re-aeration of poorly and non-aerated lung regions compared to a control group.

Although quantitative CT scan analysis remains the reference method for computing lung recruitment, it requires dedicated software and manual delineation of the perimeter of the lungs in each CT image [72]. To increase the feasibility of the use of CT, Chiumello and colleagues [72] demonstrated that visual anatomical analysis of lung CT had a good accuracy in detecting patients with high or low recruitability.

CT could also be applied to evaluate the possible changes in lung aeration with different types of mechanical ventilation. Yoshida and colleagues showed [73] that airway pressure release ventilation significantly increased and decreased the normally aerated and non-aerated lung regions, respectively, compared to pressure support ventilation. Mentzelopoulos and colleagues [74] compared high frequency oscillation ventilation with and without tracheal gas insufflation. The addition of tracheal gas insufflation significantly decreased the poorly and non-aerated regions mainly located in the lower dependent part of the lung.

\section{Lung ultrasound}

Similar to CT, LUS could be an alternative technique for assessing changes in lung morphology during a PEEP trial. Stefanidis and colleagues [75] estimated the size of non-aerated tissue in dependent lung regions at different PEEP levels. Similar to the estimation of lung recruitment from CT scans, only non-inflated lung regions were considered. The LUS analysis showed good intra/ inter-observer agreement, with a mean bias of $0.002 \pm$ 0.34 and $-0.06 \pm 0.47 \mathrm{~cm}^{2}$. Increases in PEEP caused a reduction in non-aerated lung regions and an increase in oxygenation. In addition, LUS, using scores based on the number of B lines, can monitor extension of pulmonary 
edema, the amount of extravascular lung water, and the corresponding decrease in lung aeration [76,77]. In pulmonary edema, the ultrasound score is based on the number of vertical B lines detected from the anterior and lateral parts of the chest wall $[78,79]$ on four intercostal spaces on the right side, and three in the left side; coalescent vertical $\mathrm{B}$ lines are considered present if there are $10 \mathrm{~B}$ lines. The LUS score is significantly correlated to extravascular lung water measured by gravimetry [80], the indicator dilution method [76] or CT [81].

A high correlation was found between the LUS reaeration score and quantitative CT analysis in patients with ventilator-associated pneumonia [38]. In patients with ARDS and/or pneumonia, consolidated lung areas predominating in dependent lung regions coexist with interstitial and alveolar edema in anterior and lateral
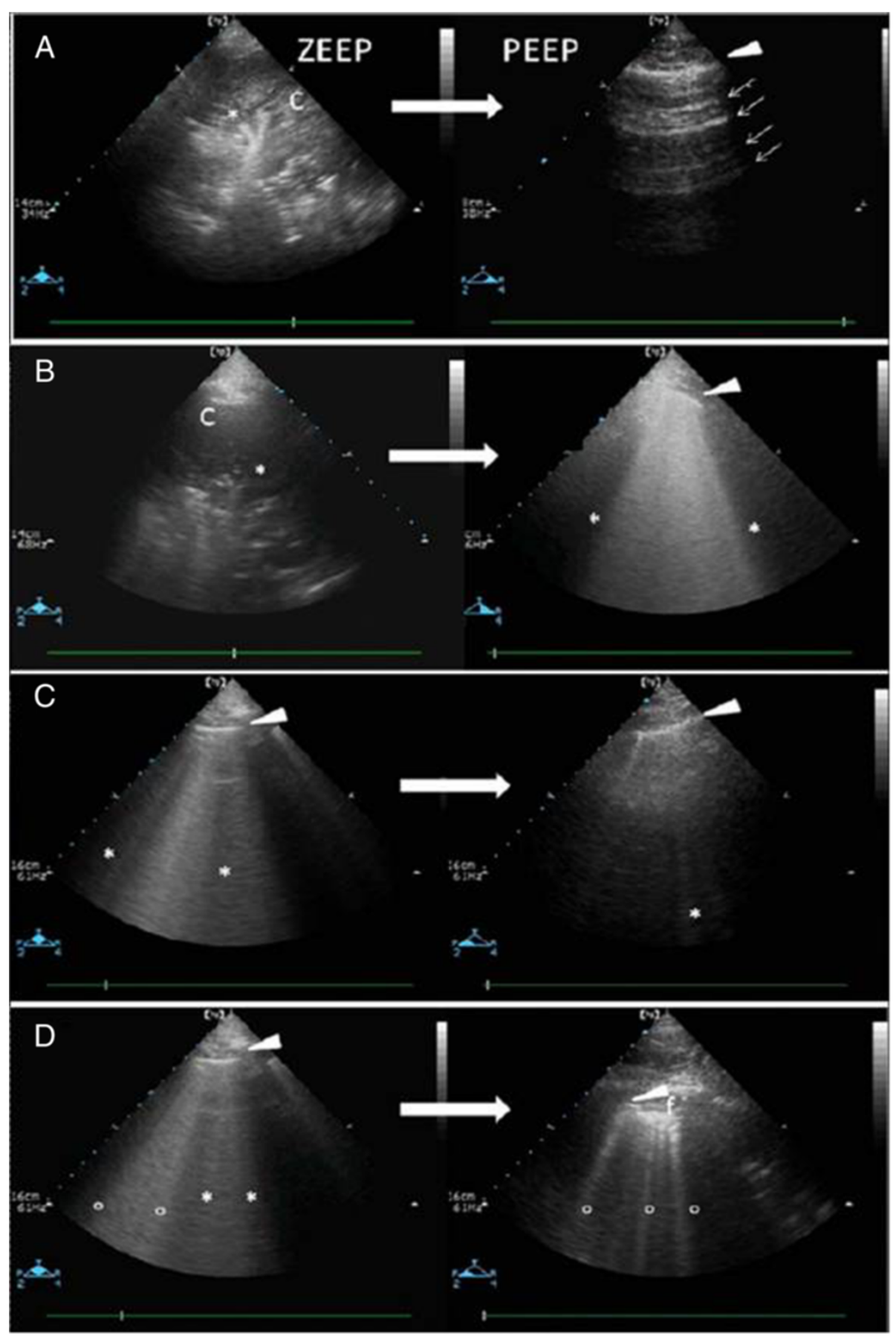

Figure 3 (See legend on next page.) 
(See figure on previous page.)

Figure 3 Illustration of positive end-expiratory pressure (PEEP)-induced lung recruitment detected by ultrasound. (A) Left: transverse view of consolidated lower lobe. Lung consolidation appears as a tissue structure $(C)$, and hyperechoic tubular images (star) can be seen, corresponding to dynamic air bronchograms (air-filled bronchi). Right: after PEEP $15 \mathrm{cmH}_{2} \mathrm{O}$, the same lung region appears normally aerated. The pleural line (white arrow) can be seen with multiple horizontal A lines (thin arrows). (B) Left: transverse view of consolidated lower lobe. Lung consolidation appears as a tissue structure (C), and hyperechoic punctiform images (star) can be seen, corresponding to static air bronchograms (air-filled bronchi). Right: after PEEP $15 \mathrm{cmH}_{2} \mathrm{O}$, the same lung region is characterized by multiple coalescent $\mathrm{B}$ lines (B2 lines), attesting to the penetration of gas within the consolidation. The pleural line is visible (white arrow), as well as coalescent B lines (stars) arising from the pleural line and spreading up to the edge of the screen. These artifacts correspond to ground-glass areas on chest computed tomography. (C) Left: transverse view of a lung region with alveolar syndrome. Coalescent B lines (stars) arising from the pleural line (white arrow) are present. Right: After PEEP $15 \mathrm{cmH}_{2} \mathrm{O}$, the same lung region appears normally aerated. The pleural line (white arrow) can be seen with an isolated B line (star). (D) Left: transverse view of a lung region with pneumonia. Coalescent B lines (B2 lines) arising from the pleural line (white arrow and stars) or from a juxtapleural consolidation (white circles) are present. Right: after PEEP $15 \mathrm{cmH}_{2} \mathrm{O}$, the same lung region is characterized by multiple welldefined and irregularly spaced B lines (B1 lines), attesting of the penetration of additional gas within the lung region. B1 lines (white circles) arise from juxtapleural consolidations, suggesting the presence of small foci of pneumonia. [82] Copyright@2013 American Thoracic Society. ZEEP; zero-EPP.

lung regions. The LUS re-aeration score should include dependent lung regions, which are frequently consolidated. LUS examination is performed on 12 regions of interest, including upper and lower posterior regions. In each region examined, changes in ultrasound pattern following therapeutic intervention are detected and numbers are attributed as follows: from multiple $\mathrm{B}$ lines to normal, from coalescent B lines to multiple B lines, and from consolidation to coalescent B lines, 1 point; from coalescent $B$ lines to normal, or from consolidation to multiple B lines, 3 points; from consolidation to normal, 5 points. The mean LUS re-aeration score is then calculated for the 12 regions examined [38,82]. This score takes into account not only consolidated lung regions but also lung regions with moderate and severe loss of inflation [67]. Using this score, Mentzelopoulos and colleagues [74] and Bouhemad and colleagues [82] showed that a lung aeration score computed by LUS was able to predict lung recruitment similarly to the pressure volume curve analysis. Figure 3 shows the different LUS patterns after PEEP-induced lung recruitment.

\section{Electrical impedance tomography}

By computing the potentially recruitable lung volume as the difference between the open, fully recruited and the not recruited lung volume at $40 \mathrm{cmH}_{2} \mathrm{O}$, Lowhagen and colleagues [83] observed a mean potentially recruitable lung volume of $26 \pm 11 \%$ (range 11 to $47 \%$ ) in ARDS patients. In this line, Grychtol and colleagues [84] proposed a fuzzy logic-based algorithm to analyze EIT images obtained during stepwise changes of mean airway pressure to identify alveolar opening of collapsed regions, overdistension of previously functional areas, collapse of previously opened alveolar regions and the recovery of previously overdistended alveoli. The EIT could also be used to evaluate intratidal regional gas distribution, offering additional information on lung recruitment at different PEEP levels. Lowhagen and colleagues [85] analyzed intratidal regional gas distribution with changes in regional lung mechanics using EIT and airway pressure data at different levels of PEEP. Independent of PEEP level, the tidal volume was mainly distributed in the mid-ventral regions, although when PEEP was increased there was a mean redistribution of gas from ventral to dorsal regions, with great variability among subjects. Although these data are not entirely new, they suggest the use of EIT at the bedside could be a clinical tool for following, breath by breath, regional ventilation distribution [86]. However, no study has compared lung recruitment measured with EIT and lung $\mathrm{CT}$ at different PEEP levels. In an experimental animal model of ARDS comparing lung recruitment estimated by EIT during constant flow inflation as the slope of global impedance time and the dynamic CT scan, only a moderate correlation was found. In an animal model of lung injury, EIT-guided ventilation, where regional EITderived compliance was used to maximize recruitment of dependent lung and minimize overdistention of nondependent lung areas, resulted in improved respiratory mechanics, greater recruitment, improved gas exchange, and reduced histologic evidence of ventilator-induced lung injury [87]. A comparison between a CT scan and an EIT image for the detection of regional distribution of ventilation is shown in Figure 4.

\section{Overdistension \\ Computed tomography}

Quantitative lung CT defined lung overdistensions as lung regions with a density threshold below -900 Hounsfield units [88]. This value comes from healthy subjects in whom, at total lung capacity, the large increase in lung volume was characterized by CT-derived values below this threshold. In addition, this threshold was also related to function tests and histologic findings in patients with emphysema [89]. However, both modifying the size of the voxel by changing the $\mathrm{CT}$ section thickness and the type of reconstruction filter can significantly affect the quantitative computation of lung 


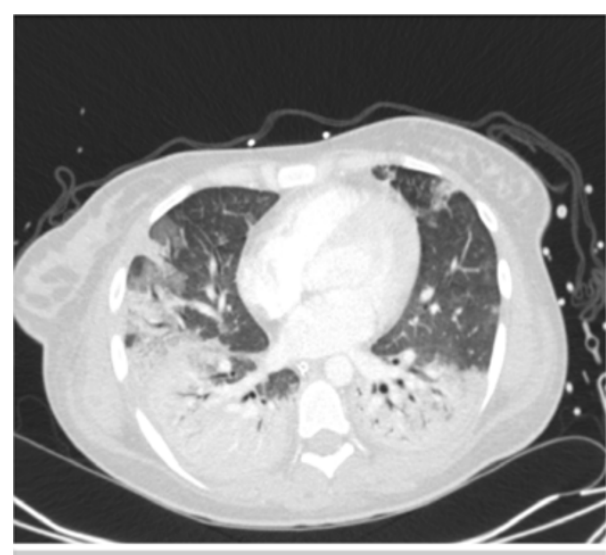

Right lung
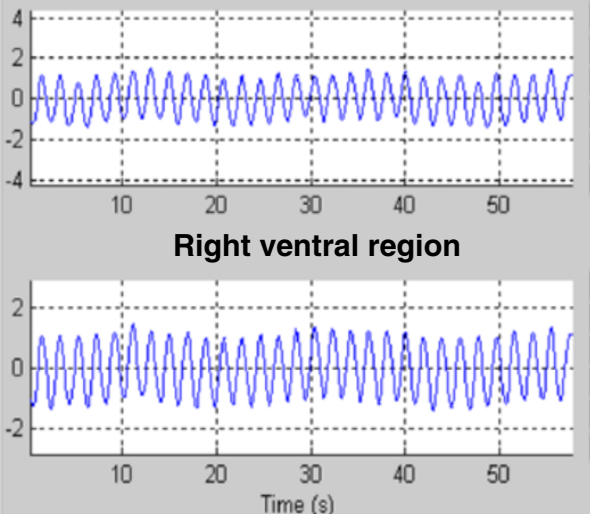

Right dorsal region
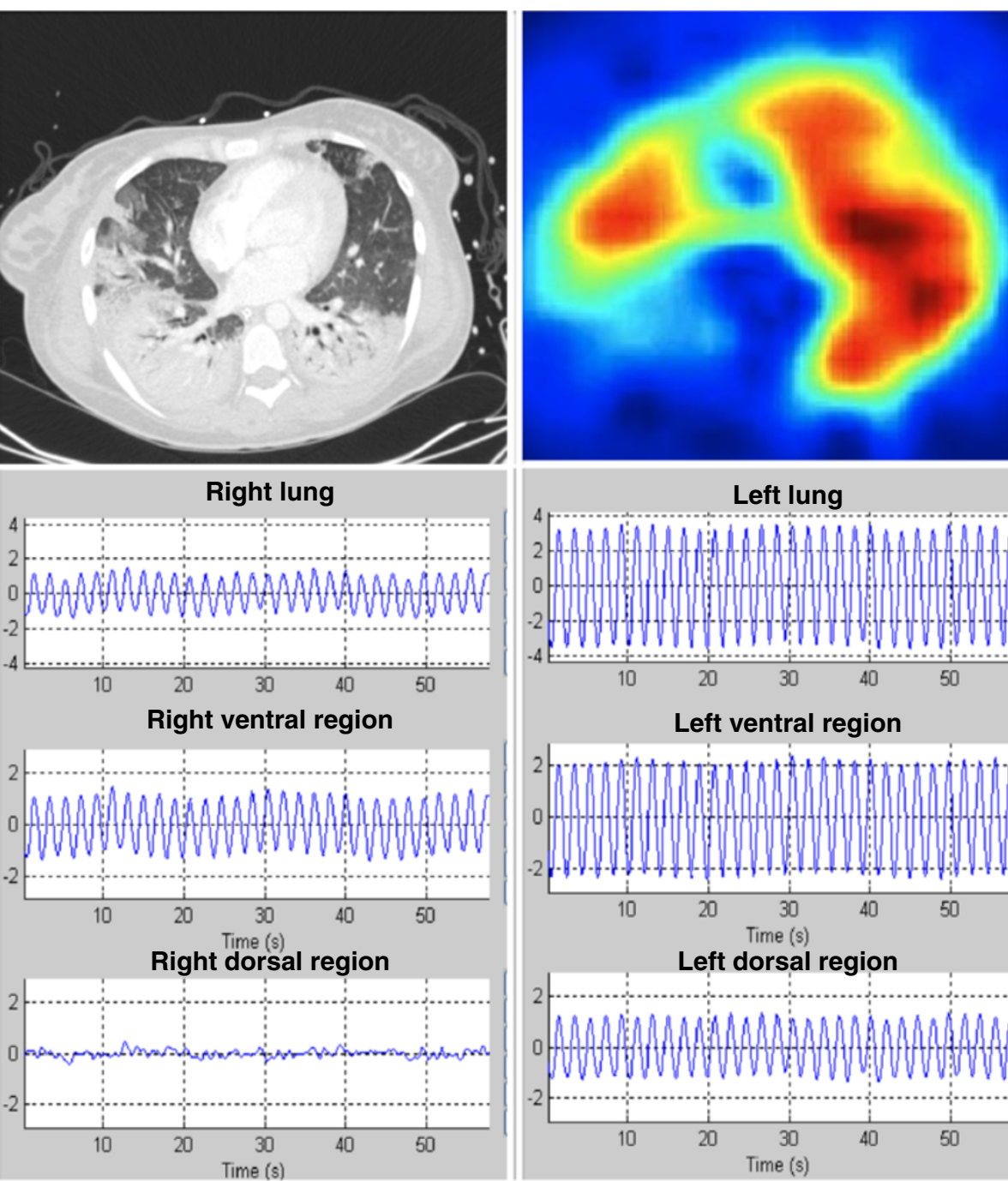

Left lung
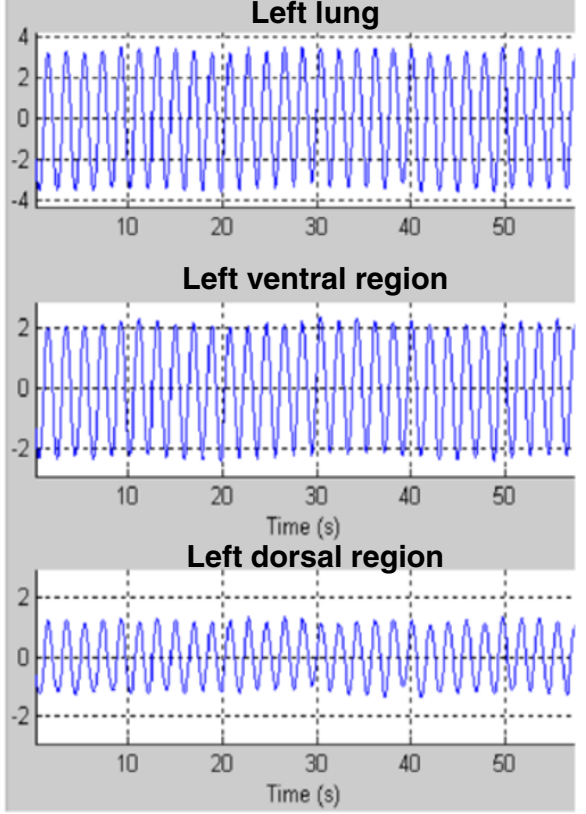

Figure 4 Comparison between a computed tomography scan (left upper panel) and an electrical impedance tomography (EIT) image (right upper panel). The EIT image depicts regional changes in electrical resistivity (impedance) represented by a colour thermal scale. The scale ranges from the colour red (indicating maximal tidal impedance change) to blue (indicating no change in impedance). The lower panels show tidal variations of impedance for each lung region. The regional inhomogeneity in impedance, with a loss of ventilation mainly in the right dorsal region, is due, in this example, to consolidation of the lung parenchyma. The advantage of EIT is that the image might change following recruitment maneuvers, physiotherapy or prone positioning, indicating a response to such treatments.

overinflation $[88,90]$. A thick CT section $(10 \mathrm{~mm})$ underestimates the overinflated lung volume by 3 to $5 \%$ compared to thin CT sections $(1.5 \mathrm{~mm})$ [88]. Lung overinflation has been reported in up to $44 \%$ of ARDS patients, usually located in the caudal and nondependent lung regions [91]. Lung overdistension during mechanical ventilation is a risk factor for ventilatorinduced lung injury, and it can promote the generation of air cystis and bronchiectasis in the same anatomical lung regions [92].

In ARDS, hyperinflation (that is, strain) is related to the amount of tidal volume and PEEP applied to the resting lung volume. In patients with focal loss of lung aeration, high PEEP and recruitment maneuver induce predominantly hyperinflation rather than lung recruitment $[6,22,25]$. Consequently, by applying the same tidal volume in patients with different resting lung volumes, different strain will be generated [69]. Terragni and colleagues [50] evaluated the effect of a ventilatory strategy (according to ARDSnet) involving lung hyperinflation in ARDS patients with large dependent non-aerated lung regions. Although the airway plateau pressure was always lower than $30 \mathrm{cmH}_{2} \mathrm{O}$, one-third of the patients presented a substantial tidal hyperinflation, especially patients with an airway plateau pressure between 28 and $30 \mathrm{cmH}_{2} \mathrm{O}$. 


\section{Lung perfusion}

\section{Lung ultrasound}

Color Doppler sonography applied in the chest can assess qualitative parameters (direction and characteristics of blood flow) and quantitative parameters (resistive and pulsatility index) $[93,94]$. Quantitative analysis of blood flow has been used to assess the etiology of pulmonary lesions. Pneumonia is characterized by a marked treelike vascularity with increased resistive index [93]. However, the flow signal in pulmonary lesions is limited by cardiac pulsation and respiratory movements [94]. No flow signal can be detected by color Doppler sonography in up to $20 \%$ of pulmonary lesions [94].

\section{Computed tomography}

An important objective in the setting of mechanical ventilation is to optimally match ventilation with lung perfusion in order to improve gas exchange. Using an electron beam CT scanner, Dakin and colleagues [95] analyzed the distribution of parenchymal consolidation and tissue perfusion in healthy and ARDS patients. Contrary to healthy subjects, in whom perfusion showed a gravitational bias, increasing along the anterior-posterior ordinate, perfusion was quite inhomogeneously distributed in ARDS patients. In ARDS a greater proportion of blood flow was directed towards the collapsed area, as quantified by dynamic CT. This amount of shunt was significantly related to the severity of hypoxemia.

\section{Electrical impedance tomography}

As perfusion-related changes in thoracic impedance are about one order of magnitude smaller than the changes induced by ventilation, it is much more difficult to extract information on lung perfusion. A promising method to quantify lung perfusion (pulsatile and nonpulsatile components) involves the injection of a contrast agent that possesses much higher electrical conductivity than lung tissues (for example, hypertonic saline). Through mathematical calculations of first-pass kinetics of the impedance-time dilution curve, it has been possible to estimate pulmonary perfusion in a way that correlated with single-photon emission computed tomography [96]. This technique is limited, however, because assessment of perfusion cannot happen continuously but only by a bolus and the frequency of the measurement is restricted by the potential side effects caused by the use of saline at high concentration.

\section{Outcome}

\section{Computed tomography}

The influence of lung morphology on outcome was clearly demonstrated 13 years ago [97]. Although several studies have described the lung morphology in ARDS, only a few have evaluated the relationship between CT findings and patient survival [27]. Among a large series of ARDS patients with an overall mortality of $46 \%$, patients with diffuse attenuations on lung CT had a significantly higher mortality rate compared to those with lobar and patchy attenuations (75\% versus $41 \%$ and $42 \%$ ) [97]. Chung and colleagues [98], exploring the extension of lung abnormalities in the early phase of ARDS, found that non-survivors presented a higher amount of lung involvement without any differences in consolidation and ground area opacity extensions. Similarly, in severe ARDS due to H1N1 infection, non-survivors had a significantly higher CT score (computed from the extension and type of lung abnormalities) compared to survivors, with an optimal cutoff of 100 to predict short-term mortality [99].

In addition to high short-term mortality, ARDS patients are also characterized at 6 and 12 months by a possible reduction in quality of life and functional status [100]. Masclans and colleagues [101] evaluated lung abnormalities in ARDS survivors at 6 months using high resolution CT scans. Morphologic alterations were detected in $76 \%$ of the patients, with reticular and groundglass patterns the most frequent abnormalities; however, these alterations were limited to less than $25 \%$ of lung parenchyma. Similar results were also reported at 12 months by Chiumello and colleagues [100], who found that non-aerated and poorly aerated lung regions were limited to $8 \%$ and $16 \%$ of the total lung. The almost complete regression of lung parenchyma involvement was also found in survivors of ARDS due to H1N1, in whom lung fibrosis was present in less than $5 \%$ of patients [102].

\section{Risks of intra-hospital transport to the radiology department}

Lung imaging techniques that cannot be provided in the ICU (CT, PET or MRI) require the transport of patients to the radiologic department. Consequently, possible benefits obtained from the diagnostic information should be higher compared to the possible adverse events arising from the transport. Despite significant improvements in intra-hospital transport, the incidence of adverse events has been found to be between $8 \%$ and $68 \%$ depending on the estimated seriousness of the patient's condition [103]. In a cross-sectional analysis of intra-hospital transport incidents collected over 6 years in 93 ICUs, 191 incidents were reported. However, only $31 \%$ of the cases resulted in a significantly adverse outcome, with major physiological derangement in 15\% and cardiac arrest in 3\% [104]. Among related factors, transport equipment failure, lack of supervision by the transport team and the seriousness of patients' conditions were the most significant predictor factors [104]. Consequently, several scientific societies have developed 
guidelines for the intra-hospital transport of critically ill patients [105-107]. Dedicated equipment and specific training are crucial to reduce the occurrence of possible adverse events during transport, especially in intubated and ventilated patients.

\section{Risks of X-ray irradiation}

The development of spiral CT in the late 1980s significantly contributed to an increase in the number of $\mathrm{CT}$ examinations [108]. However, the use of CT is associated with X-ray radiation exposure. Exposure to low-dose radiation, although not able to cause immediate harm, can be associated with long-term harmful effects [109]. A straightforward link between low-level radiation exposure from $\mathrm{CT}$ and potential radiation risks has not been established. As an example, the International Commission on Radiological protection suggested 50 additional fatal cancers are induced per million people exposed to $1 \mathrm{mSv}$ of medical radiation (standard lung CT is associated with $8 \mathrm{mSv}$ ) [110]. In contrast the French Academy of Science did not find enough evidence to make an association between increased cancer risk and the low radiation dose used for chest CT [111]. A quite recent observational study in 15 countries reported an excess relative risk of cancer mortality that was dose-dependent [112]. At the present time, it should be safe to discourage unnecessary CT testing. The new multi-detector row CT will contribute to further increase the quality of the images with less radiation dose [113].

\section{Conclusion}

Lung imaging has significantly changed our understanding and management of ARDS. In addition to classic radiologic techniques that require the transportation of patients outside the ICU, new techniques such as transthoracic LUS and EIT could offer, at the bedside, an easy, alternative way to monitor the respiratory impact of mechanical ventilation and to select the most protective ventilator settings.

\section{Abbreviations \\ 18-FDG: [18F]-fluoro-2-deoxy-D-glucose; ARDS: Acute respiratory distress syndrome; CT: Computed tomography; EIT: Electrical impedance tomography; LUS: Lung ultrasound; MRI: Magnetic resonance imaging; PEEP: Positive end-expiratory airway pressure; PET: Positron emission tomography.}

\section{Competing interests}

The authors declare that they have no competing interests.

\section{Authors' contributions}

DC conceived the structure of the manuscript, was involved in drafting the manuscript and revised it critically for important intellectual content. SC and SF performed the computerized search and were involved in drafting the sections concerning X-ray imaging, computed tomography and positron emission tomography and in revising the complete manuscript critically. BB was involved in drafting the sections concerning lung ultrasound technique and in revising the complete manuscript critically. LC was involved in drafting the sections concerning electrical impedance tomography and magnetic resonance imaging and in revising the complete manuscript critically. All authors read and approved the final manuscript.

\section{Author details}

'Dipartimento di Anestesia, Rianimazione (Intensiva e Subintensiva) e Terapia del Dolore, Fondazione IRCCS Ca' Granda - Ospedale Maggiore Policlinico, Via F. Sforza 35, Milan, Italy. ${ }^{2}$ Multidisciplinary Critical Care Unit, La Pitié-Salpêtrière Hospital, University Pierre and Marie Curie Paris, Paris, France. ${ }^{3}$ Guy's and St Thomas' NHS Foundation Trust, St Thomas' Hospital, London, UK.

Published: 18 Nov 2013

\section{References}

1. Ashbaugh DG, Bigelow DB, Petty $T L$, Levine BE: Acute respiratory distress in adults. Lancet 1967, 2:319-323.

2. Camporota L, Ranieri VM: What's new in the "Berlin" definition of acute respiratory distress syndrome? Minerva Anestesiol 2012, 78:1162-1166.

3. Ferguson ND, Fan E, Camporota L, Antonelli M, Anzueto A, Beale R, Brochard L, Brower R, Esteban A, Gattinoni L, Rhodes A, Slutsky AS, Vincent JL, Rubenfeld GD, Thompson BT, Ranieri VM: The Berlin definition of ARDS: an expanded rationale, justification, and supplementary material. Intensive Care Med 2012, 38:1573-1582.

4. Ranieri VM, Rubenfeld GD, Thompson BT, Ferguson ND, Caldwell E, Fan E, Camporota L, Slutsky AS: Acute respiratory distress syndrome: the Berlin Definition. JAMA 2012, 307:2526-2533.

5. Bellani G, Mauri T, Pesenti A: Imaging in acute lung injury and acute respiratory distress syndrome. Curr Opin Crit Care 2012, 18:29-34.

6. Constantin J: Lung imaging in patients with acute respiratory distress syndrome: from an understanding of pathophysiology to bedside monitoring. Minerva Anestesiol 2012, 79:176-184.

7. Dushianthan A, Grocott MP, Postle AD, Cusack R: Acute respiratory distress syndrome and acute lung injury. Postgrad Med J 2011, 87:612-622.

8. Aberle DR, Brown K: Radiologic considerations in the adult respiratory distress syndrome. Clin Chest Med 1990, 11:737-754.

9. Pinilla I, de Gracia MM, Quintana-Diaz M, Figueira JC: Radiological prognostic factors in patients with pandemic H1N1 (pH1N1) infection requiring hospital admission. Emerg Radiol 2011, 18:313-319.

10. Lichtenstein D, Goldstein I, Mourgeon E, Cluzel P, Grenier P, Rouby JJ: Comparative diagnostic performances of auscultation, chest X-ray, and lung ultrasonography in acute respiratory distress syndrome. Anesthesiology 2004, 100:9-15.

11. Xirouchaki N, Magkanas E, Vaporidi K, Kondili E, Plataki M, Patrianakos A, Akoumianaki E, Georgopoulos D: Lung ultrasound in critically ill patients: comparison with bedside chest X-ray. Intensive Care Med 2011, 37:1488-1493.

12. Endo S, Shibata S, Sato N, Hashiba E, Tajimi K, Saito K, Kawamae K, Nakane M, Murakawa M: A prospective cohort study of ALI/ARDS in the Tohoku district of Japan (second report). J Anesth 2010, 24:351-358.

13. Rice TW, Ware LB, Haponik EF, Chiles C, Wheeler AP, Bernard GR, Steingrub $J S$, Hite RD, Matthay MA, Wright P, Ely EW: Vascular pedicle width in acute lung injury: correlation with intravascular pressures and ability to discriminate fluid status. Crit Care 2011, 15:R86.

14. Gattinoni L, Presenti A, Torresin A, Baglioni S, Rivolta M, Rossi F, Scarani F, Marcolin R, Cappelletti G: Adult respiratory distress syndrome profiles by computed tomography. J Thorac Imaging 1986, 1:25-30.

15. Gattinoni L, Caironi P, Pelosi P, Goodman LR: What has computed tomography taught us about the acute respiratory distress syndrome? Am J Respir Crit Care Med 2001, 164:1701-1711.

16. Rouby JJ, Puybasset L, Nieszkowska A, Lu Q: Acute respiratory distress syndrome: lessons from computed tomography of the whole lung. Crit Care Med 2003, 31:S285-\$295.

17. Puybasset L, Cluzel P, Gusman P, Grenier P, Preteux F, Rouby JJ: Regional distribution of gas and tissue in acute respiratory distress syndrome. I. Consequences for lung morphology. CT Scan ARDS Study Group. Intensive Care Med 2000, 26:857-869.

18. Rouby JJ, Lu Q, Goldstein I: Selecting the right level of positive endexpiratory pressure in patients with acute respiratory distress syndrome. Am J Respir Crit Care Med 2002, 165:1182-1186. 
19. Hubmayr RD: Perspective on lung injury and recruitment: a skeptical look at the opening and collapse story. Am J Respir Crit Care Med 2002, 165:1647-1653.

20. Rouby JJ, Lu Q, Vieira S: Pressure/volume curves and lung computed tomography in acute respiratory distress syndrome. Eur Respir J Suppl 2003, 42:27s-36s.

21. Rouby JJ, Constantin JM, Roberto De AG, Zhang M, Lu Q: Mechanical ventilation in patients with acute respiratory distress syndrome. Anesthesiology 2004, 101:228-234.

22. Puybasset L, Gusman P, Muller JC, Cluzel P, Coriat P, Rouby JJ: Regional distribution of gas and tissue in acute respiratory distress syndrome. III. Consequences for the effects of positive end-expiratory pressure. CT Scan ARDS Study Group. Adult Respiratory Distress Syndrome. Intensive Care Med 2000, 26:1215-1227.

23. Constantin JM, Cayot-Constantin S, Roszyk L, Futier E, Sapin V, Dastugue B, Bazin JE, Rouby JJ: Response to recruitment maneuver influences net alveolar fluid clearance in acute respiratory distress syndrome. Anesthesiology 2007, 106:944-951.

24. Constantin JM, Jaber S, Futier E, Cayot-Constantin S, Verny-Pic M, Jung B, Bailly A, Guerin R, Bazin JE: Respiratory effects of different recruitment maneuvers in acute respiratory distress syndrome. Crit Care 2008, 12:R50

25. Constantin JM, Grasso S, Chanques G, Aufort S, Futier E, Sebbane M, Jung B, Gallix B, Bazin JE, Rouby JJ, Jaber S: Lung morphology predicts response to recruitment maneuver in patients with acute respiratory distress syndrome. Crit Care Med 2010, 38:1108-1117.

26. Galiatsou E, Kostanti E, Svarna E, Kitsakos A, Koulouras V, Efremidis SC, Nakos G: Prone position augments recruitment and prevents alveolar overinflation in acute lung injury. Am J Respir Crit Care Med 2006, 174:187-197.

27. Sheard $S$, Rao $P$, Devaraj A: Imaging of acute respiratory distress syndrome. Respir Care 2012, 57:607-612.

28. Wang S, Ruan Z, Zhang J, Jin W: The value of pulmonary contusion volume measurement with three-dimensional computed tomography in predicting acute respiratory distress syndrome development. Ann Thorac Surg 2011, 92:1977-1983.

29. Strumwasser A, Chu E, Yeung L, Miraflor E, Sadjadi J, Victorino GP: A novel $\mathrm{CT}$ volume index score correlates with outcomes in polytrauma patients with pulmonary contusion. J Surg Res 2011, 170:280-285.

30. Reske AW, Reske AP, Gast HA, Seiwerts M, Beda A, Gottschaldt U, Josten C, Schreiter D, Heller N, Wrigge H, Amato MB: Extrapolation from ten sections can make CT-based quantification of lung aeration more practicable. Intensive Care Med 2010, 36:1836-1844.

31. Gattinoni L, Cressoni M: Quantitative CT in ARDS: towards a clinical tool? Intensive Care Med 2010, 36:1803-1804.

32. Gardelli G, Feletti F, Nanni A, Mughetti M, Piraccini A, Zompatori M: Chest ultrasonography in the ICU. Respir Care 2012, 57:773-781.

33. Agricola E, Arbelot C, Blaivas M, Bouhemad B, Copetti R, Dean A, Dulchavsky S, Elbarbary M, Gargani L, Hoppmann R, Kirkpatrick AW, Lichtenstein D, Liteplo A, Mathis G, Melniker L, Neri L, Noble VE, Petrovic T, Reissig A, Rouby JJ, Seibel A, Soldati G, Storti E, Tsung JW, Via G, Volpicelli G: Ultrasound performs better than radiographs. Thorax 2011, 66:828-829.

34. Bouhemad B, Zhang M, Lu Q, Rouby JJ: Clinical review: Bedside lung ultrasound in critical care practice. Crit Care 2007, 11:205.

35. Remerand F, Dellamonica J, Mao Z, Ferrari F, Bouhemad B, Jianxin Y, Arbelot C, Lu Q, Ichai C, Rouby JJ: Multiplane ultrasound approach to quantify pleural effusion at the bedside. Intensive Care Med 2010, 36:656-664.

36. Volpicelli G, Elbarbary M, Blaivas M, Lichtenstein DA, Mathis G, Kirkpatrick AW, Melniker L, Gargani L, Noble VE, Via G, Dean A, Tsung JW, Soldati G, Copetti R, Bouhemad B, Reissig A, Agricola E, Rouby JJ, Arbelot C, Liteplo A, Sargsyan A, Silva F, Hoppmann R, Breitkreutz R, Seibel A, Neri L, Storti E, Petrovic T: International evidence-based recommendations for point-ofcare lung ultrasound. Intensive Care Med 2012, 38:577-591.

37. Via G, Storti E, Gulati G, Neri L, Mojoli F, Braschi A: Lung ultrasound in the ICU: from diagnostic instrument to respiratory monitoring tool. Minerva Anestesiol 2012, 78:1282-1296.

38. Bouhemad B, Liu ZH, Arbelot C, Zhang M, Ferarri F, Le Guen M, Girard M, Lu Q, Rouby JJ: Ultrasound assessment of antibiotic-induced pulmonary reaeration in ventilator-associated pneumonia. Crit Care Med 2010, 38:84-92.

39. Copetti R, Soldati G, Copetti P: Chest sonography: a useful tool to differentiate acute cardiogenic pulmonary edema from acute respiratory distress syndrome. Cardiovasc Ultrasound 2008, 6:16.
40. Cianchi G, Bonizzoli M, Pasquini A, Bonacchi M, Zagli G, Ciapetti M, Sani G, Batacchi S, Biondi S, Bernardo P, Lazzeri C, Giovannini V, Azzi A, Abbate R, Gensini G, Peris A: Ventilatory and ECMO treatment of H1N1-induced severe respiratory failure: results of an Italian referral ECMO center. BMC Pulm Med 2011, 11:2

41. Bellani G, Amigoni M, Pesenti A: Positron emission tomography in ARDS: a new look at an old syndrome. Minerva Anestesiol 2011, 77:439-447.

42. Musch G: Positron emission tomography: a tool for better understanding of ventilator-induced and acute lung injury. Curr Opin Crit Care 2011, 17:7-12.

43. de Prost N, Tucci MR, Melo MF: Assessment of lung inflammation with 18F-FDG PET during acute lung injury. AJR Am J Roentgenol 2010, 195:292-300.

44. Bellani G, Messa C, Guerra L, Spagnolli E, Foti G, Patroniti N, Fumagalli R, Musch G, Fazio F, Pesenti A: Lungs of patients with acute respiratory distress syndrome show diffuse inflammation in normally aerated regions: a [18F]-fluoro-2-deoxy-D-glucose PET/CT study. Crit Care Med 2009, 37:2216-2222.

45. Rodrigues RS, Miller PR, Bozza FA, Marchiori E, Zimmerman GA, Hoffman JM, Morton KA: FDG-PET in patients at risk for acute respiratory distress syndrome: a preliminary report. Intensive Care Med 2008, 34:2273-2278.

46. Caironi P, Cressoni M, Chiumello D, Ranieri M, Quintel M, Russo SG, Cornejo R, Bugedo G, Carlesso E, Russo R, Caspani L, Gattinoni L: Lung opening and closing during ventilation of acute respiratory distress syndrome. Am J Respir Crit Care Med 2010, 181:578-586.

47. Dreyfuss D, Saumon G: Ventilator-induced lung injury: lessons from experimental studies. Am J Respir Crit Care Med 1998, 157:294-323.

48. Kolobow T, Moretti MP, Fumagalli R, Mascheroni D, Prato P, Chen V, Joris M: Severe impairment in lung function induced by high peak airway pressure during mechanical ventilation. An experimental study. Am Rev Respir Dis 1987, 135:312-315.

49. de Prost N, Dreyfuss D: How to prevent ventilator-induced lung injury? Minerva Anestesiol 2012, 78:1054-1066.

50. Terragni PP, Rosboch G, Tealdi A, Corno E, Menaldo E, Davini O, Gandini G, Herrmann P, Mascia L, Quintel M, Slutsky AS, Gattinoni L, Ranieri VM: Tidal hyperinflation during low tidal volume ventilation in acute respiratory distress syndrome. Am J Respir Crit Care Med 2007, 175:160-166.

51. Bellani G, Guerra L, Musch G, Zanella A, Patroniti N, Mauri T, Messa C, Pesenti A: Lung regional metabolic activity and gas volume changes induced by tidal ventilation in patients with acute lung injury. Am J Respir Crit Care Med 2011, 183:1193-1199.

52. Chen DL, Bedient TJ, Kozlowski J, Rosenbluth DB, Isakow W, Ferkol TW, Thomas B, Mintun MA, Schuster DP, Walter MJ: [18F]fluorodeoxyglucose positron emission tomography for lung antiinflammatory response evaluation. Am J Respir Crit Care Med 2009, 180:533-539.

53. Bodenstein M, David M, Markstaller K: Principles of electrical impedance tomography and its clinical application. Crit Care Med 2009, 37:713-724.

54. Bayford RH: Bioimpedance tomography (electrical impedance tomography). Annu Rev Biomed Eng 2006, 8:63-91.

55. Leonhardt S, Lachmann B: Electrical impedance tomography: the holy grail of ventilation and perfusion monitoring? Intensive Care Med 2012, 38:1917-1929.

56. Muders T, Luepschen H, Putensen C: Impedance tomography as a new monitoring technique. Curr Opin Crit Care 2010, 16:269-275.

57. Hinz J, Hahn G, Neumann P, Sydow M, Mohrenweiser P, Hellige G, Burchardi $\mathrm{H}$ : End-expiratory lung impedance change enables bedside monitoring of end-expiratory lung volume change. Intensive Care Med 2003, 29:37-43.

58. Lundin S, Stenqvist O: Electrical impedance tomography: potentials and pitfalls. Curr Opin Crit Care 2012, 18:35-41

59. Cereda M, Emami K, Kadlecek S, Xin Y, Mongkolwisetwara P, Profka H, Barulic A, Pickup S, Mansson S, Wollmer P, Ishii M, Deutschman CS, Rizi RR: Quantitative imaging of alveolar recruitment with hyperpolarized gas MRI during mechanical ventilation. J Appl Physiol 2011, 110:499-511.

60. Kauczor HU: MRI of the Lung. Berlin: Springer; 2009

61. Matsuoka S, Hunsaker AR, Gill RR, Jacobson FL, Ohno Y, Patz S, Hatabu H: Functional MR imaging of the lung. Magn Reson Imaging Clin N Am 2008, 16:275-289.

62. Hopkins SR: Functional magnetic resonance imaging of the lung: a physiological perspective. J Thorac Imaging 2004, 19:228-234. 
63. Emami K, Stephen M, Kadlecek S, Cadman RV, Ishii M, Rizi RR: Quantitative assessment of lung using hyperpolarized magnetic resonance imaging. Proc Am Thorac Soc 2009, 6:431-438.

64. Wallet F, Delannoy B, Haquin A, Debord S, Leray V, Bourdin G, Bayle F, Richard JC, Boussel L, Guerin C: Evaluation of recruited lung volume at inspiratory plateau pressure with PEEP using bedside digital chest X-ray in patients with acute lung injury/ARDS. Respir Care 2013, 58:416-423.

65. Rouby JJ, Arbelot C, Brisson H, Lu Q, Bouhemad B: Measurement of alveolar recruitment at the bedside: the beginning of a new era in respiratory monitoring? Respir Care 2013, 58:539-542.

66. Gattinoni L, Pelosi P, Crotti S, Valenza F: Effects of positive end-expiratory pressure on regional distribution of tidal volume and recruitment in adult respiratory distress syndrome. Am J Respir Crit Care Med 1995, 151:1807-1814.

67. Malbouisson LM, Muller JC, Constantin JM, Lu Q, Puybasset L, Rouby JJ: Computed tomography assessment of positive end-expiratory pressureinduced alveolar recruitment in patients with acute respiratory distress syndrome. Am J Respir Crit Care Med 2001, 163:1444-1450.

68. Luecke T, Corradi F, Pelosi P: Lung imaging for titration of mechanical ventilation. Curr Opin Anaesthesiol 2012, 25:131-140.

69. Chiumello D, Carlesso E, Cadringher P, Caironi P, Valenza F, Polli F, Tallarin F, Cozzi P, Cressoni M, Colombo A, Marini JJ, Gattinoni L: Lung stress and strain during mechanical ventilation for acute respiratory distress syndrome. Am J Respir Crit Care Med 2008, 178:346-355.

70. Bruhn A, Bugedo D, Riquelme F, Varas J, Retamal J, Besa C, Cabrera C, Bugedo G: Tidal volume is a major determinant of cyclic recruitmentderecruitment in acute respiratory distress syndrome. Minerva Anestesiol 2011, 77:418-426.

71. Lu Q, Zhang M, Girardi C, Bouhemad B, Kesecioglu J, Rouby JJ: Computed tomography assessment of exogenous surfactant-induced lung reaeration in patients with acute lung injury. Crit Care 2010, 14:R135.

72. Chiumello D, Marino A, Brioni M, Menga F, Cigada I, Lazzerini M, Andrisan MC, Biondetti P, Cesana B, Gattinoni L: Visual anatomical lung CT scan assessment of lung recruitability. Intensive Care Med 2012, 39:66-73.

73. Yoshida T, Rinka H, Kaji A, Yoshimoto A, Arimoto H, Miyaichi T, Kan M: The impact of spontaneous ventilation on distribution of lung aeration in patients with acute respiratory distress syndrome: airway pressure release ventilation versus pressure support ventilation. Anesth Analg 2009, 109:1892-1900.

74. Mentzelopoulos SD, Theodoridou M, Malachias S, Sourlas S, Exarchos DN, Chondros D, Roussos C, Zakynthinos SG: Scanographic comparison of high frequency oscillation with versus without tracheal gas insufflation in acute respiratory distress syndrome. Intensive Care Med 2011, 37:990-999.

75. Stefanidis K, Dimopoulos S, Tripodaki ES, Vitzilaios K, Politis P, Piperopoulos $P$, Nanas S: Lung sonography and recruitment in patients with early acute respiratory distress syndrome: a pilot study. Crit Care 2011, 15:R185.

76. Agricola E, Bove T, Oppizzi M, Marino G, Zangrillo A, Margonato A, Picano E: "Ultrasound comet-tail images": a marker of pulmonary edema: a comparative study with wedge pressure and extravascular lung water. Chest 2005, 127:1690-1695.

77. Agricola E, Picano E, Oppizzi M, Pisani M, Meris A, Fragasso G, Margonato A: Assessment of stress-induced pulmonary interstitial edema by chest ultrasound during exercise echocardiography and its correlation with left ventricular function. J Am Soc Echocardiogr 2006, 19:457-463.

78. Gargani L: Lung ultrasound: a new tool for the cardiologist. CardiovasC Ultrasound 2011, 9:6.

79. Jambrik Z, Monti S, Coppola V, Agricola E, Mottola G, Miniati M, Picano E: Usefulness of ultrasound lung comets as a nonradiologic sign of extravascular lung water. Am J Cardiol 2004, 93:1265-1270.

80. Jambrik Z, Gargani L, Adamicza A, Kaszaki J, Varga A, Forster T, Boros M, Picano E: B-lines quantify the lung water content: a lung ultrasound versus lung gravimetry study in acute lung injury. Ultrasound Med Biol 2010, 36:2004-2010.

81. Baldi G, Gargani L, Abramo A, D’Errico L, Caramella D, Picano E, Giunta F, Forfori F: Lung water assessment by lung ultrasonography in intensive care: a pilot study. Intensive Care Med 2013, 39:74-84.

82. Bouhemad B, Brisson H, Le Guen M, Arbelot C, Lu Q, Rouby JJ: Bedside ultrasound assessment of positive end-expiratory pressure-induced lung recruitment. Am J Respir Crit Care Med 2011, 183:341-347.
83. Lowhagen $\mathrm{K}$, Lindgren $\mathrm{S}$, Odenstedt $\mathrm{H}$, Stenqvist $\mathrm{O}$, Lundin S: A new nonradiological method to assess potential lung recruitability: a pilot study in ALI patients. Acta Anaesthesiol Scand 2011, 55:165-174

84. Grychtol B, Wolf GK, Adler A, Arnold JH: Towards lung EIT image segmentation: automatic classification of lung tissue state from analysis of EIT monitored recruitment manoeuvres. Physiol Meas 2010, 31:S31-S43.

85. Lowhagen K, Lundin S, Stenqvist O: Regional intratidal gas distribution in acute lung injury and acute respiratory distress syndrome - assessed by electric impedance tomography. Minerva Anestesiol 2010, 76:1024-1035.

86. Domenighetti G, Maggiorini M: Electrical impedance tomography to guide ventilation in ALI-ARDS patients: a research tool for zealous physiologists or an imminent support for the real world intensivist? Minerva Anestesiol 2010, 76:986-988.

87. Wolf GK, Gomez-Laberge C, Rettig JS, Vargas SO, Smallwood CD, Prabhu SP, Vitali SH, Zurakowski D, Arnold JH: Mechanical ventilation guided by electrical impedance tomography in experimental acute lung injury. Crit Care Med 2013, 41:1296-1304.

88. Vieira SR, Puybasset L, Richecoeur J, Lu Q, Cluzel P, Gusman PB, Coriat P, Rouby JJ: A lung computed tomographic assessment of positive endexpiratory pressure-induced lung overdistension. Am J Respir Crit Care Med 1998, 158:1571-1577.

89. Gevenois PA, De Vuyst P, de Maertelaer V, Zanen J, Jacobovitz D, Cosio MG, Yernault JC: Comparison of computed density and microscopic morphometry in pulmonary emphysema. Am J Respir Crit Care Med 1996 154:187-192.

90. Reske AW, Busse H, Amato MB, Jaekel M, Kahn T, Schwarzkopf P, Schreiter $D$, Gottschaldt U, Seiwerts M: Image reconstruction affects computer tomographic assessment of lung hyperinflation. Intensive Care Med 2008 34:2044-2053

91. Nieszkowska A, Lu Q, Vieira S, Elman M, Fetita C, Rouby JJ: Incidence and regional distribution of lung overinflation during mechanical ventilation with positive end-expiratory pressure. Crit Care Med 2004, 32:1496-1503.

92. Treggiari MM, Romand JA, Martin JB, Suter PM: Air cysts and bronchiectasis prevail in nondependent areas in severe acute respiratory distress syndrome: a computed tomographic study of ventilatorassociated changes. Crit Care Med 2002, 30:1747-1752.

93. Gorg C, Bert T: Transcutaneous colour Doppler sonography of lung consolidations: review and pictorial essay. Part 2: colour Doppler sonographic patterns of pulmonary consolidations. Ultraschall Med 2004 25:285-291

94. Gorg C, Bert T: Transcutaneous colour Doppler sonography of lung consolidations: review and pictorial essay. Part 1: pathophysiologic and colour Doppler sonographic basics of pulmonary vascularity. Ultraschall Med 2004, 25:221-226.

95. Dakin J, Jones AT, Hansell DM, Hoffman EA, Evans TW: Changes in lung composition and regional perfusion and tissue distribution in patients with ARDS. Respirology 2011, 16:1265-1272.

96. Borges JB, Suarez-Sipmann F, Bohm SH, Tusman G, Melo A, Maripuu E, Sandstrom M, Park M, Costa EL, Hedenstierna G, Amato M: Regional lung perfusion estimated by electrical impedance tomography in a piglet model of lung collapse. J Appl Physiol 2012, 112:225-236.

97. Rouby JJ, Puybasset L, Cluzel P, Richecoeur J, Lu Q, Grenier P: Regional distribution of gas and tissue in acute respiratory distress syndrome. II. Physiological correlations and definition of an ARDS Severity Score. CT Scan ARDS Study Group. Intensive Care Med 2000, 26:1046-1056.

98. Chung JH, Kradin RL, Greene RE, Shepard JA, Digumarthy SR: CT predictors of mortality in pathology confirmed ARDS. Eur Radiol 2011, 21:730-737.

99. Grieser C, Goldmann A, Steffen IG, Kastrup M, Fernandez CM, Engert U, Deja M, Lojewski $C$, Denecke T: Computed tomography findings from patients with ARDS due to Influenza A (H1N1) virus-associated pneumonia. Eur J Radiol 2012, 81:389-394.

100. Chiumello D, Taccone P, Berto V, Marino A, Migliara G, Lazzerini M, Gattinon $L$ : Long-term outcomes in survivors of acute respiratory distress syndrome ventilated in supine or prone position. Intensive Care Med 2012 38:221-229.

101. Masclans JR, Roca O, Munoz X, Pallisa E, Torres F, Rello J, Morell F: Quality of life, pulmonary function, and tomographic scan abnormalities after ARDS. Chest 2011, 139:1340-1346.

102. Chiumello D, Marino A, Lazzerini M, Caspani ML, Gattinoni L: Lung recruitability in ARDS H1N1 patients. Intensive Care Med 2010, 36:1791-1792. 
103. Fanara B, Manzon C, Barbot O, Desmettre T, Capellier G: Recommendations for the intra-hospital transport of critically ill patients. Crit Care 2010, 14:R87.

104. Beckmann U, Gillies DM, Berenholtz SM, Wu AW, Pronovost P: Incidents relating to the intra-hospital transfer of critically ill patients. An analysis of the reports submitted to the Australian Incident Monitoring Study in Intensive Care. Intensive Care Med 2004, 30:1579-1585.

105. Guidelines for the transfer of critically ill patients. Guidelines Committee of the American College of Critical Care Medicine; Society of Critical Care Medicine and American Association of Critical-Care Nurses Transfer Guidelines Task Force. Crit Care Med 1993, 21:931-937.

106. Intensive Care Society: Guidelines for the transport of the critically ill adult. [http://www.ics.ac.uk/ics-homepage/guidelines-standards/].

107. SIAARTI Study Group for Safety in Anesthesia and Intensive Care: Recommendations on the transport of critically ill patient. [http://www.siaarti. it/lineeguida/pdf_img/file_42.pdf].

108. Mayo JR: Radiation dose issues in longitudinal studies involving computed tomography. Proc Am Thorac Soc 2008, 5:934-939.

109. Shah DJ, Sachs RK, Wilson DJ: Radiation-induced cancer: a modern view. Br J Radiol 2012, 85:e1166-e1173.

110. International Commission on Radiological Protection: ICRP-60. Recommendations of the International Commission on Radiological Protection. Oxford: Pergamon Press; 1991.

111. Institut de France Academie des Sciences: Dose-effect relationships and estimation of the carcinogenic effects of low doses of ionizing radiation. [www.academie-sciences.fr/activite/rapport/rapport070405.pdf].

112. Cardis E, Vrijheid M, Blettner M: The 15-Country Collaborative Study of Cancer Risk among Radiation Workers in the Nuclear Industry: estimates of radiation-related cancer risks. Radiat Res 2007, 167:396-416.

113. Mayo JR, Aldrich J, Muller NL: Radiation exposure at chest CT: a statement of the Fleischner Society. Radiology 2003, 228:15-21.

\section{$10.1186 /$ cc13114}

Cite this article as: Chiumello et al:: Clinical review: Lung imaging in acute respiratory distress syndrome patients - an update. Critical Care $2013,17: 243$ 